\title{
Better recovery from lameness among dairy cows housed in hospital pens
}

\author{
Peter T. Thomsen, ${ }^{1 *} \odot$ Katrine K. Fogsgaard, ${ }^{1}$ Margit Bak Jensen, ${ }^{1} \odot$ Peter Raundal, $^{2}$ and Mette S. Herskin ${ }^{1} \odot$ \\ ${ }^{1}$ Department of Animal Science, Aarhus University, DK-8830 Tjele, Denmark \\ ${ }^{2}$ SEGES, Livestock Innovation, DK-8200 Aarhus N, Denmark
}

\section{ABSTRACT}

Housing in hospital pens may be beneficial for lame cows due to soft flooring and less competition for resources. We compared recovery from lameness among dairy cows housed in designated hospital pens, with deep-litter straw, with recovery among cows housed together with the rest of the lactating cows in their home pens, with cubicles and slatted or solid concrete floors. Additionally, we compared lying behavior in the 2 groups of cows. A total of 168 lame dairy cows from 5 herds were included in the study. Each herd was visited once weekly, and lame cows (locomotion score 3 or 4 on a 5-point scale) were examined in a hoof-trimming chute, trimmed, and randomly assigned to 1 of 2 treatments: housing in a hospital pen (termed "treatment"; 72 cows) or housing under the herds' standard conditions together with the rest of the lactating cows in the herd (termed "control"; 96 cows). Cows were locomotion scored weekly until they were no longer lame or until they had been part of the trial for 3 weeks (i.e., 2, 3, or 4 locomotion scorings per cow). We categorized cows to describe the progression of lameness over time: recovery (divided into fast, medium, or slow), improvement without recovery, constant lameness, or worsening of lameness. Lying behavior was recorded in a sample of 60 of the 168 cows for a period of $5 \mathrm{~d}$. Overall, recovery from lameness was significantly different between treatment and control cows. The proportion of cows included in the study with locomotion score 4 and a subsequent improvement was significantly higher among treatment cows than among control cows. Among cows included with locomotion score $4,40 \%$ of treatment cows also had a locomotion score 4 at the fourth locomotion scoring, $46 \%$ had improved to a score 3 , and $14 \%$ were no longer lame. In comparison, $73 \%$ of control cows had a locomotion score 4 at the fourth locomotion scoring, $16 \%$ had improved to a score 3 , and $11 \%$ were no longer lame. We found no differences between treatment and

Received May 31, 2019.

Accepted August 26, 2019.

*Corresponding author: ptt@anis.au.dk control cows for mean daily lying time, number of steps per day, number of daily lying bouts, or mean duration of lying bouts. Housing of lame dairy cows in a hospital pen with a soft surface, easier access to feed and water, a smaller group size, and reduced waiting time for milking may have positive effects on recovery from lameness. Typically, farmers have housed only severely lame cows in hospital pens. However, our results indicate that less severely lame cows may also benefit from a stay in a hospital pen.

Key words: dairy cow, hospital pen, lameness, recovery

\section{INTRODUCTION}

Lameness constitutes a major problem in dairy production in many countries. High prevalences of lame cows have been reported worldwide: examples include 29\% (Denmark; Thomsen et al., 2012), 45\% (United States; Chapinal et al., 2013), 21\% (Canada; Solano et al., 2015), 28\% (United Kingdom; Griffiths et al., 2018), and $43 \%$ (Brazil; Costa et al., 2018). Lameness in cows is associated with decreased animal welfare (Whay, 2002) and financial losses for the dairy farmer (Bruijnis et al., 2010; Charfeddine and Pérez-Cabal, 2017). Research has indicated that lame cows may benefit fromand prefer - cubicles with a soft surface (Tucker et al., 2003; Cook et al., 2004; Gomez and Cook, 2010). Cows housed on deep-litter straw have been shown to have more lying bouts, indicating greater ease of changing position, compared with cows housed in a cubicle system (Fregonesi and Leaver, 2001; Campler et al., 2018). Additionally, lame cows may have difficulty competing for resources such as feed, water, and access to lying places (Norring et al., 2014; Barker et al., 2018). Housing in a hospital pen may be beneficial for lame cows. The floor in a hospital pen is typically soft, providing good lying comfort. Stocking density and number of cows in the group are often lower, which ensures easier access to resources. Additionally, hospital pens may facilitate the farmer's observation, monitoring, and treatment of lame cows.

Some countries have recommendations (National Farm Animal Care Council, Canada, 2009) or require- 
ments (e.g., National Assembly for Wales, 2007; Danish Ministry of Food and Agriculture, 2017) for the availability and design of hospital pens in dairy herds. Still, knowledge about the use of hospital pens for dairy cows is relatively limited. Houe et al. (2016) evaluated the availability and use of hospital pens in Danish dairy herds and found that $91 \%$ of a sample of 130 herds had at least 1 hospital pen: $78 \%$ had hospital pen(s) for individual cows, and $65 \%$ had hospital pen(s) for groups of cows. Fogsgaard et al. (2016) conducted a questionnaire survey among U.S. dairy farmers in Iowa and found that $82 \%$ of 112 respondents had "facilities to house a sick or injured dairy cow away from her normal pen or stall." Relatively often, farmers reported that sick cows were not housed in a designated hospital pen but, rather, together with cows around calving (close up, calving, or fresh cows) or dry cows. When asked about the likelihood of moving cows with specific diagnoses to a hospital pen, $14 \%$ of the surveyed farmers stated that they always moved a lame cow to a hospital pen or a special-needs area, and $64 \%$ stated they did so sometimes. When farmers were asked about their most recently treated sick or injured cow, lameness was the most frequently stated diagnosis $(27 \%$ of all cases). Approximately half of these lame cows had been housed in a hospital pen or a special-needs area (Fogsgaard et al., 2016).

To our knowledge, only 2 studies have evaluated the behavior of lame cows in hospital pens. Jensen et al. (2015) and Bak et al. (2016) studied the same sample of lame cows housed individually in experimental hospital pens. Each hospital pen was divided into 2 otherwise equal parts: half covered by a rubber mat and half with deep-bedded sand. Jensen et al. (2015) found that lame cows preferred the deep-bedded sand for lying. Additionally, they found that the lame cows preferred to lie near companion animals kept in a neighboring pen. Bak et al. (2016) found that lame cows had fewer difficulties lying down on sand compared with rubber, and that cows lay down for longer on sand, suggesting that it was more comfortable for lame cows to lie on.

The objective of the present study was to compare recovery from lameness among dairy cows housed in designated hospital pens, with deep-litter straw, with recovery among cows housed together with the rest of the lactating cows in their home pens, with cubicles and slatted or solid concrete floors. Additionally, we compared lying behavior in the 2 groups of cows. We hypothesized that cows would recover better from lameness when housed in a hospital pen compared with housing together with lactating herdmates. Additionally, we hypothesized that cows in hospital pens would lie down for longer.

\section{MATERIALS AND METHODS}

From August 2016 to November 2017, we conducted a controlled randomized trial in 5 commercial dairy herds to evaluate the association between housing in hospital pens and recovery from lameness. In brief, each herd was visited once weekly, and lame cows were randomly assigned to 1 of 2 treatments: housing in a hospital pen (termed "treatment") or housing under standard conditions together with the rest of the lactating cows in the herd (termed "control"). Cows were locomotion scored weekly until they were no longer lame or until they had been part of the trial for 3 wk (i.e., 2, 3, or 4 locomotion scorings per cow).

Five Danish dairy herds were recruited for the study by convenience sampling and the following inclusion criteria: (1) indoor loose housing all year round (no summer grazing) and (2) availability of a suitable hospital pen (see criteria below).

Table 1 presents descriptive characteristics of the 5 herd included in the study. In all herds, the ratios between cows and cubicles were close to 1 (range: 0.97 to 1.06 cubicles per cow). The space available at the feed bunk ranged between 0.49 and $0.65 \mathrm{~m}$ per cow.

At the weekly herd visit, an observer identified lame lactating cows during a pen walk in all pens with lactating cows in the herd. Cows were locomotion scored by 1 of 2 observers, using the 5 -point locomotion scoring system described by Thomsen et al. (2008), with the following categories: (1) normal, (2) uneven gait, (3) mild lameness, (4) lameness, or (5) severe lameness. The observers had extensive experience with the scoring system and were calibrated before, as well as halfway through, the study period. To test interobserver agreement, the observers independently scored 20 cows at each of the 2 test herd visits, with a percent agreement of $95 \%$ and $85 \%$, respectively. Percent agreement is considered acceptable when greater than or equal to $75 \%$ (Burn and Weir, 2011; Schlageter-Tello et al., 2015). At the weekly herd visits, all cows scored in a herd were locomotion scored by the same observer. The observer continued locomotion scoring in the herd until he had identified a sufficient number of lame cows to fill all available places in treatment and control groups. Cows with locomotion scores 3 and 4 were defined as lame. Besides being lame, inclusion criteria for cows were as follows: (1) not previously included in the study, (2) not expected to be culled within the next month, and (3) no signs of systemic disease indicated by fever. According to Danish legislation, severely lame cows must be housed in a hospital pen, and cows with locomotion score 5 were therefore not eligible for inclusion in the study. The study was approved by the 
Danish Animal Experiments Inspectorate (permit no. 2016-15-0201-00860).

Lame cows were examined in a hoof-trimming chute the same day, and all 4 feet were evaluated to diagnose any hoof lesions. We recorded hoof lesions as described in the ICAR Claw Health Atlas (Egger-Danner et al., 2015) and, for the analyses, grouped lesions as digital dermatitis, sole ulcer, or other hoof lesions. The last group also included cows without any visible hoof lesions. If necessary, hooves were trimmed to facilitate inspection or to correct abnormalities. Any treatments of hoof lesions (e.g., application of wooden blocks or hoof bandages), were performed by the farmer based on the normal treatment standards used in the herd. The number of lame cows included in the study each week was determined by the number of vacant places in the hospital pen and the availability of lame cows and, thus, varied by week and herd. Lame cows were allocated to treatment or control groups based on random numbers generated on the observer's cell phone: an even number allocated the cow to the treatment group and an odd number to the control group.

We moved cows in the treatment group to a hospital pen immediately after examination in the hoof-trimming chute. Inclusion criteria for hospital pens were that they should (1) have a soft surface, (2) provide at least $8 \mathrm{~m}^{2}$ per cow, and (3) have at least 1 eating place per cow. All hospital pens in the study were group pens with deep-litter straw bedding. Additional details are given in Table 1. Farmers added straw when needed, typically daily, to keep the lying area soft and dry. Cows in hospital pens were fed the same TMR ad libitum as the rest of the lactating cows in the herd, and water was freely available. Treatment cows were milked in the milking parlor or automatic milking system, separately from the rest of the lactating cows, with as little waiting time as possible. In contrast, cows in the control group were housed and milked together with the rest of the lactating cows in the herd, with no special care.

All cows included in the study were locomotion scored once weekly. An employee from the herd presented the cows to the observer in a neutral place, to ensure that (1) all cows were scored on the same concrete surface and (2) the observer was blinded regarding whether the cow had come from the treatment or the control group. The duration of the study was 1,2, or 3 wk for each individual cow. Each cow thus received 2, 3, or 4 weekly locomotion scores. The maximum duration of 3 wk was decided based on the limited availability of hospital pens in the herds. Because a herd will be able to house a limited number of cows in hospital pens, cows are unlikely to be housed in hospital pens for longer periods, under practical conditions. The first locomotion score for each cow was either 3 or 4 . A cow could complete the 
Table 2. Definitions of categories describing the progression of lameness ${ }^{1}$ during up to 4 weekly locomotion scorings of lame dairy cows housed in hospital pens or used as controls

\begin{tabular}{|c|c|c|c|c|}
\hline $\begin{array}{l}\text { First locomotion } \\
\text { scoring }\end{array}$ & $\begin{array}{l}\text { Second locomotion } \\
\text { scoring }\end{array}$ & $\begin{array}{l}\text { Third locomotion } \\
\text { scoring }\end{array}$ & $\begin{array}{l}\text { Fourth locomotion } \\
\text { scoring }\end{array}$ & Category \\
\hline 3 & 1 or 2 & & & Fast recovery \\
\hline 3 & 3 or 4 & 3 or 4 & 4 & Lameness worsened \\
\hline 3 & 3 or 4 & 3 or 4 & 3 & Lameness 3 \\
\hline 4 & 1 or 2 & & & Fast recovery \\
\hline 4 & 3 or 4 & 3 or 4 & 3 & Lameness improved \\
\hline 4 & 3 or 4 & 3 or 4 & 4 & Lameness 4 \\
\hline
\end{tabular}

${ }^{1}$ Cows were locomotion scored by 1 of 2 observers, using the 5-point locomotion scoring system described by Thomsen et al. (2008), with the following categories: (1) normal, (2) uneven gait, (3) mild lameness, (4) lameness, or (5) severe lameness.

study in 2 ways: (1) by becoming non-lame (locomotion score 1 or 2 ) after 1,2 , or 3 wk in the study, or (2) by remaining lame until the end of the study (locomotion score 3 or 4 after 1, 2, and $3 \mathrm{wk}$ ). Cows with locomotion score 5 were not included in the study.

Table 2 describes the categories of progression of lameness. These categories were defined to describe the progression over time: recovery (fast, medium, or slow), improvement without recovery, constant lameness, or worsening of lameness.

We evaluated differences between progression of lameness in treatment and control cows using Fisher's exact test (PROC FREQ, SAS Version 9.3; SAS Institute Inc. Cary, NC). The statistical significance of the overall difference between treatment and control cows was tested. Additionally, differences between selected groups of cows were evaluated: cows recovering (fast vs. medium vs. slow recovery), cows with first locomotion score 4 (unchanged vs. improvement vs. recovery), cows with first locomotion score 3 (unchanged vs. worsening vs. recovery), recovery vs. no recovery, and improvement vs. worsening.

A systematic, random sample of 60 of the 168 cows were equipped with IceQube loggers (IceRobotics, Edinburgh, UK): 24 treatment cows and 36 control cows. Automatic recordings of lying behavior by IceQubes have previously been validated, as by Kok et al. (2015) and Finney et al. (2018). Depending on herd size, the number of cows with loggers in each herd ranged from 8 to 16 . The logger was attached to a hind leg during the examination in the hoof-trimming chute and remained on until the next weekly herd visit. Excluding the day of attachment and the day of removal, all 60 cows had logger recordings for 5 whole days. All measures of activity were recorded in 15-min intervals and expressed as a mean of the $5 \mathrm{~d}$. Measures of activity included daily lying time (hours per day), number of steps per day, number of daily lying bouts, and mean duration of lying bouts (hours per bout).
To take into account the possible effect of parity and DIM (Ito et al., 2014; Solano et al., 2016; Maselyne et al., 2017), we used a generalized linear mixed model (PROC MIXED, SAS Version 9.3) to evaluate the association between each measure of activity as the outcome, and treatment (treatment or control), parity (1, 2, 3, 4 or higher), lesion (digital dermatitis, sole ulcer, or other lesions), and DIM as explanatory variables. Herd was included in the model as a random effect. This model was reduced using backward elimination, and possible interactions were included in the model. The significance level was set at $P<0.05$.

\section{RESULTS}

In total, 168 cows completed the study: 72 treatment and 96 control cows. The number of cows per herd were 10, 20, 35, 51, and 52. Mean DIM for all cows were 173 for treatment cows (range: 3 to $544 \mathrm{~d}$ ) and 177 for control cows ( 3 to 698 d). For cows with loggers, mean DIM were 165 (16 to $366 \mathrm{~d}$ ) for treatment cows and 164 (3 to 356 d) for control cows. Table 3 presents the distribution of parities for all cows and for cows with loggers. Distribution of parities did not differ between treatment and control cows $(P=0.86$ for all cows, $P=$ 0.84 for logger cows). At the first locomotion scoring, $49 \%$ of treatment cows had a locomotion score 3 , and $51 \%$ had a locomotion score 4 , compared with $43 \%$ of control cows with a locomotion score 3 and $57 \%$ with a locomotion score 4 . This difference was not significant $(P=0.53)$. Both treatment and control cows had a mean rectal temperature of $38.5^{\circ} \mathrm{C}$ at the start of the study. Digital dermatitis and sole ulcers were the most prevalent lesions identified during the examination in the hoof-trimming chute: $45 \%$ of all cows had digital dermatitis, and $24 \%$ had sole ulcers. Differences between treatment and control cows were small: $39 \%$ versus $49 \%$ digital dermatitis, and $24 \%$ versus $24 \%$ sole ulcers. The proportion of cows treated with bandages 
Table 3. Distribution (\%) of parities among all cows and cows with loggers for lame cows housed in hospital pens (treatment) versus together with the rest of the lactating cows in the herd (control)

\begin{tabular}{llrrrc}
\hline & & \multicolumn{4}{c}{ Parity } \\
\cline { 3 - 6 } Item & & 1 & 2 & 3 & 4 or higher \\
\hline All cows $(\mathrm{n}=168)$ & Treatment & 15 & 33 & 25 & 26 \\
\multirow{2}{*}{ Cows with loggers $(\mathrm{n}=60)$} & Control & 19 & 30 & 28 & 23 \\
& Treatment & 8 & 50 & 25 & 17 \\
& Control & 6 & 42 & 28 & 25 \\
\hline
\end{tabular}

and wooden hoof blocks were comparable for treatment and control cows (bandages: $33 \%$ vs. $28 \%$; blocks: $1 \%$ vs. $3 \%$ ).

Figure 1 illustrates the distribution of lameness progression categories for treatment and control cows. Overall, differences between treatment and control cows were significant $(P=0.02)$. Additionally, the proportion of cows included with locomotion score 4 and a subsequent improvement was higher $(P=0.002)$ among treatment cows. Among cows included with locomotion score $4,40 \%$ of treatment cows also had a locomotion score 4 at the fourth locomotion scoring, $46 \%$ had improved to a score 3 , and $14 \%$ were no longer lame. In comparison, $73 \%$ of control cows had a locomotion score 4 at the fourth locomotion scoring, $16 \%$ had improved to a score 3 , and $11 \%$ were no longer lame. Other differences between treatment and control cows were not significant.

Table 4 presents mean daily lying time, number of steps per day, number of daily lying bouts, and mean duration of lying bouts for treatment and control cows with loggers. We found significant associations between daily lying time and parity (lowest lying time in parity $\left.3 ; F_{3.56}=3.6, P=0.02\right)$, daily lying time and lesion type (longer lying time in cows with sole ulcers; $F_{2,57}$ $=6.9, P=0.002$ ), number of daily lying bouts and DIM (fewer bouts with increasing DIM; $F_{1.57}=5.2, P$ $=0.03)$, and mean duration of lying bouts and DIM (increasing duration with increasing DIM; $F_{1,57}=10.9$, $P=0.002$ ), but no significant associations between treatment group and any of the measures of activity.

\section{DISCUSSION}

We found that significantly more lame cows housed in hospital pens had improvement in their locomotion scores compared with control cows housed together with the rest of the lactating cows in their herds. This indicates that housing in a hospital pen, with soft surface, easier access to feed and water, smaller group size, and reduced waiting time for milking, has positive effects on recovery from lameness. However, the design of the present study did not allow any inferences about which of the aforementioned factors may have affected the recovery. Even though the present study is the first to demonstrate better recovery from lameness in cows

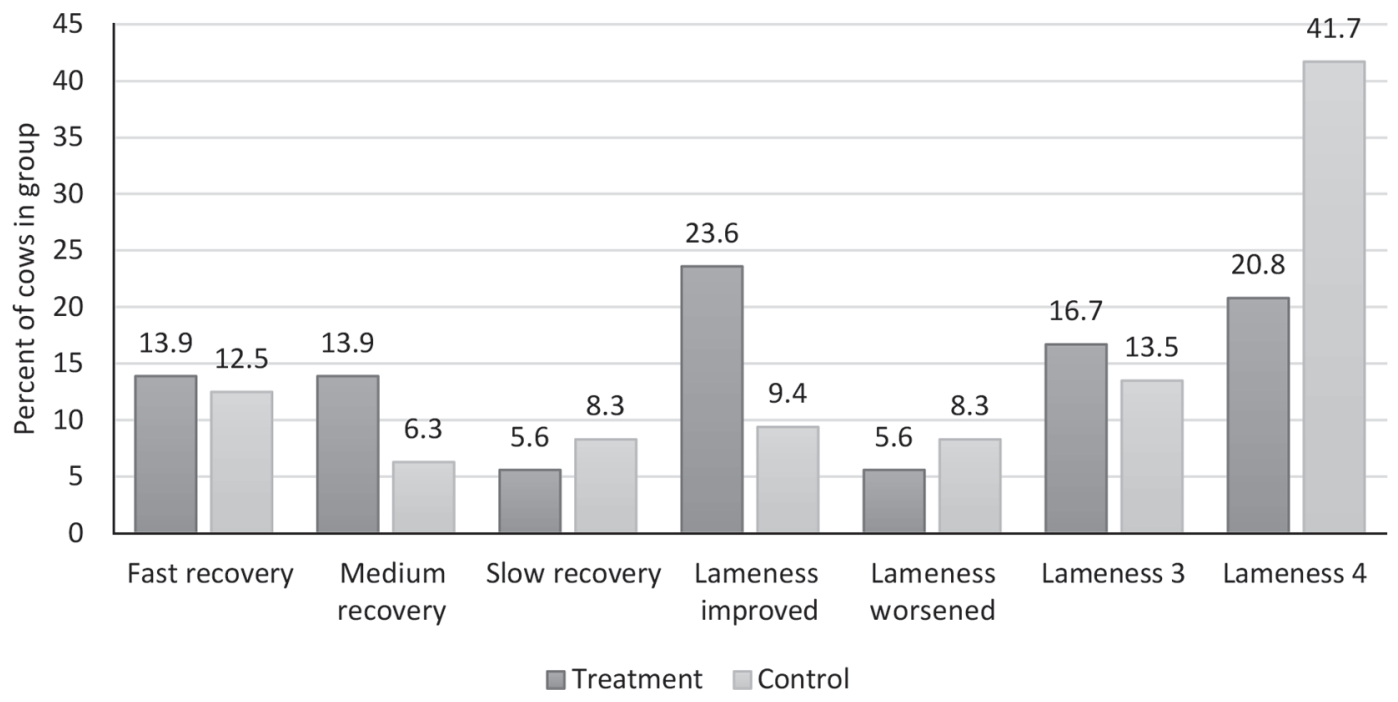

Figure 1. Distribution of categories of progression of lameness in treatment cows housed in hospital pens (dark gray) and control cows (light gray). Categories are defined in Table 2. Percents in columns add up to $100 \%$ for each group of cows. 
Table 4. Mean (range) daily lying time, number of steps per day, number of daily lying bouts, and duration of lying bouts for treatment cows housed in hospital pens $(\mathrm{n}=24)$ and control cows $(\mathrm{n}=36)$

\begin{tabular}{llccc}
\hline Item & $\begin{array}{c}\text { Daily lying time } \\
\text { (hours per day) }\end{array}$ & $\begin{array}{c}\text { Number of steps } \\
\text { (number per day) }\end{array}$ & $\begin{array}{c}\text { Number of lying bouts } \\
\text { (number per day) }\end{array}$ & $\begin{array}{c}\text { Duration of lying bouts } \\
\text { (hours per bout) }\end{array}$ \\
\hline Treatment cows & $13.5(8.6-18.1)$ & $1,257(418-2,741)$ & $12.5(7.4-18.6)$ & $1.13(0.73-1.69)$ \\
Control cows & $13.5(10.1-16.8)$ & $1,138(526-2,348)$ & $12.4(5.6-20.6)$ & $1.17(0.58-2.03)$ \\
\hline
\end{tabular}

housed in hospital pens, positive effects of soft surfaces on lameness have been demonstrated previously (e.g., Hernandez-Mendo et al., 2007). Future studies should evaluate which factors or combinations of factors affect recovery from lameness. Such studies should form the basis for recommendations for the design of hospital pens in the future. Based on the results of the present study, we recommend housing lame dairy cows in hospital pens. Typically, many farmers house only severely lame cows in hospital pens. Our results indicate that less severely lame cows may also benefit from housing in a hospital pen. However, a combination of limited availability of hospital pens and a relatively high prevalence of lame cows in many herds may be a practical limitation to the housing of all lame cows in hospital pens.

In the present study, both daily lying time and characteristics of lying bouts were comparable to results from previous studies on lame dairy cows (Ito et al., 2010; Thomsen et al., 2012; Thorup et al., 2015). The lying behavior of lame dairy cows differs from that of non-lame cows. Several studies have demonstrated that lame cows have longer daily lying time and longer duration of lying bouts than non-lame cows (e.g., Blackie et al., 2011; Thomsen et al., 2012; Solano et al., 2016). Likewise, characteristics of lying surfaces may affect lying behavior (van Gastelen et al., 2011; Ito et al., 2014). However, in the present study we found no differences in lying time, number of steps, or number or duration of lying bouts between lame cows in the treatment compared with the control group. This may indicate that the lying behavior of lame cows in the present study was influenced primarily by the lameness and to a lesser extent by the environment. Only treatment cows experienced a change in environment, as control cows were housed in their normal home pen, and this change may have counteracted an increase in lying time due to the softer surface in hospital pens.

We chose the categories for the progression of lameness (Table 2) to reflect the course of the lameness: recovery, improvement, unchanged, or worsening. To avoid categories with very few cows and to make interpretation easier, a limited number of categories were used. This meant that some simplifications had to be made. Recovery from a first locomotion score of 3 was combined with recovery from a first locomotion score of 4. Even though recovery from locomotion score 4 may be a greater improvement than recovery from locomotion score 3 , we find that this simplification was justified, given the fact that the distribution of first locomotion scores was not significantly different between treatment and control cows. Unchanged lameness during the study period was defined based on the first and last (fourth) locomotion score. This means that a cow coded as "Lameness 3" could have been scored 4 at the intermediate locomotion scorings. However, the majority of both Lameness $3(61 \%)$ and Lameness 4 (82\%) were truly constant, with identical locomotion scores throughout.

All hospital pens included in the present study were group pens designed for more than 1 cow. The optimal group size in hospital pens needs to be further evaluated. Previous research has shown that fresh cows moved to a group of 6 experienced less competition than did similar cows moved to a group of 24 (Jensen and Proudfoot, 2017). It is unclear to what degree our results are also valid for individual hospital pens. Houe et al. (2016) found that both individual and group hospital pens are common in Danish dairy herds, and research is needed to evaluate the effects of individual hospital pens. Housing lame cows in individual hospital pens may ensure even better access to resources than does housing in a group hospital pen, but possible effects of limited or no social contact in individual pens are unknown.

\section{ACKNOWLEDGMENTS}

We thank agricultural technicians Carsten Kjærulff Christensen and Henrik Krogh Andersen, Department of Animal Science, Aarhus University (Tjele, Denmark) for their valuable help with the on-farm data collection. The study was funded by the Danish Milk Levy Fund (Mælkeafgiftsfonden, Aarhus, Denmark).

\section{REFERENCES}

Bak, A. S., M. S. Herskin, and M. B. Jensen. 2016. Effect of sand and rubber surface on the lying behavior of lame dairy cows in hospital pens. J. Dairy Sci. 99:2875-2883.

Barker, Z. E., J. A. Vázquez Diosdado, E. A. Codling, N. J. Bell, H. R. Hodges, D. P. Croft, and J. R. Amory. 2018. Use of novel sensors combining local positioning and acceleration to measure feeding 
behavior differences associated with lameness in dairy cattle. J. Dairy Sci. 101:6310-6321.

Blackie, N., J. Amory, E. Bleach, and J. Scaife. 2011. The effect of lameness on lying behaviour of zero grazed Holstein dairy cattle. Appl. Anim. Behav. Sci. 134:85-91.

Bruijnis, M. R. N., H. Hogeveen, and E. N. Stassen. 2010. Assessing economic consequences of foot disorders in dairy cattle using a dynamic stochastic simulation model. J. Dairy Sci. 93:2419-2432.

Burn, C. C., and A. A. Weir. 2011. Using prevalence indices to aid interpretation and comparison of agreement ratings between two or more observers. Vet. J. 188:166-170.

Campler, M., M. B. Jensen, and L. Munksgaard. 2018. The effect of deep straw versus cubicle housing on behaviour during the dry period in Holstein cows. Appl. Anim. Behav. Sci. 209:1-7.

Chapinal, N., M. A. G. von Keyserlingk, R. L. A. Cerri, K. Ito, S. J. LeBlanc, and D. M. Weary. 2013. Herd-level reproductive performance and its relationship with lameness and leg injuries in freestall dairy herds in the northeastern United States. J. Dairy Sci. 96:7066-7072.

Charfeddine, N., and M. A. Pérez-Cabal. 2017. Effect of claw disorders on milk production, fertility, and longevity, and their economic impact in Spanish Holstein cows. J. Dairy Sci. 100:653-665.

Cook, N. B., T. B. Bennett, and K. V. Nordlund. 2004. Effect of free stall surface on daily activity patterns in dairy cows with relevance to lameness prevalence. J. Dairy Sci. 87:2912-2922.

Costa, J. H. C., T. A. Burnett, M. A. G. von Keyserlingk, and M. J. Hötzel. 2018. Prevalence of lameness and leg lesions of lactating dairy cows housed in southern Brazil: Effects of housing systems. J. Dairy Sci. 101:2395-2405.

Danish Ministry of Food and Agriculture. 2017. Ministerial order no. 58 on keeping of dairy cattle and their offspring. Accessed Sep. 27, 2019. https://www.retsinformation.dk/Forms/R0710.aspx?id= 186338.

Egger-Danner, C., P. Nielsen, A. Fiedler, K. Müller, T. Fjeldaas, D. Döpfer, V. Daniel, C. Bergsten, G. Cramer, A.-M. Christen, K. F. Stock, G. Thomas, M. Holzhauer, A. Steiner, J. Clarke, N. Capion, N. Charfeddine, J. E. Pryce, E. Oakes, J. Burgstaller, B. Heringstad, C. Ødegård, and J. Kofler. 2015. ICAR Claw Health Atlas. Accessed Sep. 27, 2019. www.icar.org/Documents/ICAR Claw_Health_Atlas.pdf

Finney, G., A. Gordon, G. Scoley, and S. J. Morrison. 2018. Validating the IceRobotics IceQube tri-axial accelerometer for measuring daily lying duration in dairy calves. Livest. Sci. 214:83-87.

Fogsgaard, K. K., M. S. Herskin, P. J. Gorden, L. L. Timms, J. K. Shearer, and S. T. Millman. 2016. Management and design of hospital pens relative to the behaviour of the compromised dairy cow: A questionnaire survey of Iowa dairy farms. Appl. Anim. Behav. Sci. 175:50-55.

Fregonesi, J. A., and J. D. Leaver. 2001. Behaviour, performance and health indicators of welfare for dairy cows housed in straw yard or free-stall systems. Livest. Prod. Sci. 68:205-216.

Gomez, A., and N. B. Cook. 2010. Time budgets of lactating dairy cattle in commercial freestall herds. J. Dairy Sci. 93:5772-5781.

Griffiths, B. E., D. Grove White, and G. Oikonomou. 2018. A crosssectional study into the prevalence of dairy cattle lameness and associated herd-level risk factors in England and Wales. Front. Vet. Sci. 5:65.

Hernandez-Mendo, O., M. A. G. von Keyserlingk, D. M. Veira, and D. M. Weary. 2007. Effects of pasture on lameness in dairy cows. J. Dairy Sci. 90:1209-1214.

Houe, H., P. T. Thomsen, C. Amdi, M. S. Herskin, B. Forkman, and M. B. Jensen. 2016. Availability and use of designated hospital pens in Danish dairy herds. Anim. Welf. 25:69-71.

Ito, K., N. Chapinal, D. M. Weary, and M. A. G. von Keyserlingk. 2014. Associations between herd-level factors and lying behaviour of freestall-housed dairy cows. J. Dairy Sci. 97:2081-2089.

Ito, K., M. A. G. von Keyserlingk, S. J. LeBlanc, and D. M. Weary. 2010. Lying behaviour as an indicator of lameness in dairy cows. J. Dairy Sci. 93:3553-3560.
Jensen, M. B., M. S. Herskin, P. T. Thomsen, B. Forkman, and H. Houe. 2015. Preferences of lame cows for type of surface and level of social contact in hospital pens. J. Dairy Sci. 98:4552-4559.

Jensen, M. B., and K. L. Proudfoot. 2017. Effect of group size and health status on behaviour and feed intake of multiparous dairy cows in early lactation. J. Dairy Sci. 100:9759-9768.

Kok, A., A. T. M. van Knegsel, C. E. van Middelaar, H. Hogeveen, B. Kemp, and I. J. M. de Boer. 2015. Validation of sensor-recorded lying bouts in lactating dairy cows using a 2 -sensor approach. J. Dairy Sci. 98:7911-7916.

Maselyne, J., M. Pastell, P. T. Thomsen, V. M. Thorup, L. Hänninen, J. Vangeyte, A. van Nuffel, and L. Munksgaard. 2017. Daily lying time, motion index and step frequency in dairy cows change throughout lactation. Res. Vet. Sci. 110:1-3.

National Assembly for Wales. 2007. The welfare of farmed animals (Wales) regulations 2007. Accessed Sep. 27, 2019. http://www .legislation.gov.uk/wsi/2007/3070/contents/made.

National Farm Animal Care Council, Canada. 2009. Code of practice for the care and handling of dairy cattle. Accessed Sep. 27, 2019. www.nfacc.ca/pdfs/codes/dairy_code_of_practice.pdf.

Norring, M., J. Häggman, H. Simojoki, P. Tamminen, C. Winckler, and M. Pastell. 2014. Lameness impairs feeding behavior of dairy cows. J. Dairy Sci. 97:4317-4321.

Schlageter-Tello, A., E. A. M. Bokkers, P. W. G. Groot Koerkamp, T. Van Hertem, S. Viazzi, C. E. B. Romanini, I. Halachmi, C. Bahr D. Berckmans, and K. Lokhorst. 2015. Relation between observed locomotion traits and locomotion score in dairy cows. J. Dairy Sci. 98:8623-8633.

Solano, L., H. W. Barkema, E. A. Pajor, S. Mason, S. J. LeBlanc, C. G. R. Nash, D. B. Haley, D. Pellerin, J. Rushen, A. M. de Passillé, E. Vasseur, and K. Orsel. 2016. Associations between lying behavior and lameness in Canadian Holstein-Friesian cows housed in freestall barns. J. Dairy Sci. 99:2086-2101.

Solano, L., H. W. Barkema, E. A. Pajor, S. Mason, S. J. LeBlanc, J. C. Zaffino Heyerhoff, C. G. R. Nash, D. B. Haley, E. Vasseur, D Pellerin, J. Rushen, A. M. de Passillé, and K. Orsel. 2015. Prevalence of lameness and associated risk factors in Canadian HolsteinFriesian cows housed in freestall barns. J. Dairy Sci. 98:6978-6991.

Thomsen, P. T., L. Munksgaard, and J. T. Sørensen. 2012. Locomotion scores and lying behaviour are indicators of hoof lesions in dairy cows. Vet. J. 193:644-647.

Thomsen, P. T., L. Munksgaard, and F. A. Tøgersen. 2008. Evaluation of a lameness scoring system for dairy cows. J. Dairy Sci. 91:119-126.

Thorup, V. M., L. Munksgaard, P.-E. Robert, H. W. Erhard, P. T. Thomsen, and N. C. Friggens. 2015. Lameness detection via legmounted accelerometers on dairy cows on four commercial farms. Animal 9:1704-1712.

Tucker, C. B., D. M. Weary, and D. Fraser. 2003. Effects of three types of free-stall surfaces on preferences and stall usage by dairy cows. J. Dairy Sci. 86:521-529.

van Gastelen, S., B. Westerlaan, D. J. Houwers, and F. J. C. M. van Eerdenburg. 2011. A study on cow comfort and risk for lameness and mastitis in relation to different types of bedding materials. J. Dairy Sci. 94:4878-4888.

Whay, H. R. 2002. Locomotion scoring and lameness detection in dairy cattle. In Pract. 24:444-449.

\section{ORCIDS}

Peter T. Thomsen @ https://orcid.org/0000-0002-0896-1610 Margit Bak Jensen ๑ https://orcid.org/0000-0001-7982-582X Mette S. Herskin (1) https://orcid.org/0000-0002-3744-4524 